\title{
James Coburn
}

Master student, Department of Teacher Education and School Development, University of Oslo

\section{Teaching Oral English Online - Through Skype (VOIP)}

\begin{abstract}
This article presents an action research study focusing on the online teaching of English conversation using VOIP (Voice Over Internet Protocol) in an unusual and challenging international online context. Information elicited from interviews with eight Conversation Facilitators shows how conversation assignments need to be designed in order to facilitate interaction patterns conducive to language learning. A range of skills and qualities likely to lead to "best practice" emerge from two interviews which are analysed in more detail. Some implications for the use of audio conferencing for the development of oral proficiency in foreign language teaching are also suggested.
\end{abstract}

\section{Introduction}

This study focuses on the teaching of English conversation to undergraduate students in Iran whereby native speakers of English function as Conversation Facilitators (CFs) using audio conferencing (Skype) to talk with small groups of students or converse one-to-one. Semi-structured interviews with eight CFs aimed to find out more about how the conversations were being conducted as well as investigating the extent to which the task design was providing an adequate basis and stimuli for the dialogues.

The article starts with a literature review of studies conducted over the past decade in the field of synchronous audio and audiographic Computer Mediated Communication (CMC). A short description of CMC activity currently under way within foreign language teaching contexts in Norway precedes a summary of the online context for the present study and the specification of the research questions. This is followed by an explanation of the rationale for the design of the conversation assignments and for the approach adopted to the analysis of the patterns of interaction found in the conversations as described in the interviews which form the main research material. An outline of the method adopted in the study is followed by a descriptive analysis of the research findings, divided into three parts: first some general findings followed by the analysis of two separate courses in which the CFs hold conversations. The discussion of the findings ends with recommendations for improving task design and practice, some of 
which have implications for foreign language teaching using audio conferencing in other online contexts.

\section{Literature review}

The past decade has witnessed an increasing number of studies on the use of audio (voice chat with the possibility of written chat), or audiographic conferencing (voice chat with multimodal possibilities including: "symbol manipulation tools such as whiteboards and concept maps" (Kenning 2010, p.4), for foreign language learning. In the past five years, in addition to studies published in journals such as CALL, ReCALL, CALICO, and Language Learning and Technology, books (Lamy \& Hampel 2007), and compilations (Belz and Thorne 2005; O'Dowd 2007; Thomas 2008; Zhang et al 2008) on online language learning have appeared with substantial sections on the use of audio and audiographic conferencing.

Research on synchronous CMC involves a variety of languages including Spanish (Volle 2005; Lee 2008), Italian (Tudini 2003), French (Lamy 2004; Hauck 2007) as well as English which is the subject of particular interest in different Asian countries including Taiwan (Chang 2007), China (Barrett 2008), Japan (Tsukamoto, Nuspliger \& Senzaki 2009), Malaysia (Maclean 2009) and Vietnam (Hong 2006) as well as in Arabic-speaking countries (Mahfous \& Ihmeideh 2009).

These studies involve audio or audiographic exchange over internet, either between students and language teachers (Hampel \& Hauck 2004, Rosell-Aguilar 2005, 2006), between students and native speakers (Tudini 2003; Chang 2007; Tsukamoto, Nuspliger \& Senzaki 2008; Barrett 2008; Lee 2008; Mahfous \& Ihmeideh 2009), between peers (Chang 2007; Yilmaz \& Granena 2010), or as "tandem" or "tridem" exchanges (Hauck 2007; O'Dowd \& Waire 2008), where students on both sides of the exchange are learning each others' language and take turns assisting one another.

This stream of new research reflects a variety of different approaches, aspects of which are all relevant to the present study: There is an increasing emphasis on the importance of task design (Kötter 2001; Rossell-Aguilar 2005; Lafford \& Lafford 2005; O'Dowd \& Waire 2009; Yilmaz \& Granenu 2010), and a growing awareness that students attempting to improve their oral language proficiency through synchronous CMC face technical challenges which can have consequences for learning outcomes (Lamy 2004), with two recent studies focusing on the anxiety which can be induced by such exchanges (Felix 2004; Arcos, Coleman \& Hampel 2009). Last but not least, there is a recognition that the difference between using simple audio (for example Skype, www.skype.com, see Appendix A for screenshot) and audiographic conferencing (see for example: Elluminate: www.elluminate.com, see Appendix A) has implications for functionality, task design and practice (Kenning, 2010). 


\section{Synchronous CMC in Norway}

At the time of writing, at least three different Norwegian institutions of higher education include audio or audiographic conferencing in foreign language learning for distance learners. Østfold College uses Elluminate for the teaching of oral French to low to upper-intermediate students. At Bergen University Spanish is taught to beginners and more advanced students using Adobe Net meeting as the audiographic platform, while The Norwegian University of Science of Technology (NTNU) in Trondheim uses Skype to teach oral Spanish and French to lower-intermediate and beginner students. In addition, many Norwegian schools participate in EU-funded and other language development projects using audio exchanges. In the future, the trend of using synchronous CMC to help develop learners' oral proficiency is likely to accelerate. Therefore, this paper can be seen as relevant to practitioners, planners and policy-makers in the field.

\section{The online context for this study}

In the present study, audio conferencing (Skype) is used by volunteer Conversation Facilitators (CFs) around the world to teach oral English to university undergraduates in Iran who are not permitted to attend ordinary universities. The university offering the courses is the Bahá'í Institute for Higher Education (hereafter referred to as "the Institute". See www.bihe.org).

Poor internet connections limit the practical design of conversation assignments since the average student's bandwidth cannot support multimedia graphics in addition to audio. Therefore, the CFs and students utilise written Skype chat as a supplement to VOIP (Voice Over Internet Protocol).

The conversations are part of a comprehensive series of English as a Foreign Language (EFL) courses being taught fully online with no face-to-face contact. The courses have been designed and developed in the broad tradition of Communicative Language Teaching (CLT), in which meaningful content and real world relevance are the main focus (Candlin \& Mercer, 2001; Savignon 2002).

At the time of this study, the Institute had two EFL courses which included conversations, with lower-intermediate (EFL101) and intermediate students (EFL102). Each course has a specially created CD using Flash technology, divided into sections for reading, writing, grammar and listening. Some of the sections have multiple-choice automated exercises. Each course lasts 16-20 weeks and course content is built up on a main theme which is further divided into modules with sub-topics. The content of the conversation assignments is closely linked to these sub-topics (see Appendix B for overview of the themes and sub-topics for EFL101 and EFL102).

The courses are taught by qualified EFL teachers who correct students' written assignments, and by native or near-native bilingual speakers (PersianEnglish) who function as CFs. This division is a result of the Institute EFL 
teachers generally not having time to do conversations as well as correct written work. In general the CFs have little or no contact with the EFL teachers. Although issues arising from this division of labour between the EFL teachers and the CFs do have important consequences, discussing these is beyond the scope of the present study.

After an initial interview, new CFs study training materials (see appendix C for excerpts) and attend a group training conducted through Skype. These CFs are then assigned experienced CFs as mentors for their first semester.

All CFs are also required to have high-speed internet connections which partially compensate for the students' poor or very poor connections. The length and quality of the Skype calls vary greatly. Some last only 20 minutes, while others continue for two hours. Conversations are often interrupted by technical problems due to the state of telecommunications and the political situation in Iran.

When using Skype, the CFs tend to decide themselves how many students to talk to at one time. Those CFs who are more technically adept or who have students with better connections try to use Skype with two, three, four or even more students. The CFs who have less experience or facility with technology tend to talk one-to-one, though bad lines can sometimes also force technicallysavvy CFs to do individualized conversations.

\section{Definition and goal of the Institute conversations}

In the Institute conversations, the term "conversation" is used as a kind of catchall, covering a very wide variety of usage and requiring a range of interactive skills. Informal conversation can develop into more or less formal discussion and vice versa. The Common European Framework for Languages (CEFR 2001) classifies conversation separately from both informal and formal discussion, but in the BIHE conversations, all of these categories are classed as conversation.

The goal of the Institute conversations is to increase students' oral proficiency defined in terms of fluency, accuracy and complexity (Skehan 1996). Since the Institute CFs are not EFL teachers, the Institute decided to focus primarily on trying to increase students' fluency, broadly defined in terms of building students' abilities to talk in chunks without excessive support.

Last, because the Institute EFL courses were new, it was vital to find out how the conversations were progressing, and what improvements were needed. Hence the present study which focuses on the following two research questions:

1. How and to what extent do the Institute's topic-based conversation assignment questions provide an adequate foundation and sufficient stimuli to assist the development of dialogues and patterns of interaction which facilitate language learning? 
2. Which pedagogical and technical skills do Conversation Facilitators need to develop in order to allow them to facilitate dialogues and patterns of interaction which promote language learning?

\section{Theoretical approach}

\section{Task Design and ZPD}

Vygotsky's concept of 'zones of proximal development' ( ZPD) is key to an understanding of the Institute's students' progress since they, as language learners, are only able to notice language problems, repair errors and progress towards self-regulation with the assistance of more knowledgeable others if the language they encounter is on an appropriate level relative to their socially mediated ZPD. (See for example the description of the levels below, consistent with, and above the learner's ZPD described in Aljaafreh \& Lantolf, 1994, p.470). It is the design of the Institute conversation tasks, and the skills of the CFs which largely determine the extent to which conversations are mediated within the students' ZPDs.

\section{Communicative language teaching, task design and the negotiation of meaning}

Within Communicative Language Teaching (CLT), the value of using tasks for communicative activities has gained widespread acceptance (Pica 1994; Doughty \& Long 2003). Definitions of what constitutes a task in CLT vary, but there is agreement that the concept broadly refers to meaningful activities, relating to real-life, having definite outcomes (Nunan 2005, pp.2-3; Skehan in Nunan 2005; Clapper, in Rossell-Aguilar, 2005, p.3). Such tasks may be convergent (Duff 1986, in Ur 1996, p.5) and therefore strongly structured leading to a definite outcome (eg completing a jigsaw task) or they may be more weakly structured, divergent and open-ended.

An influential study by Pica et al (1993), suggested that in convergent tasks where learners are 'pushed' to produce language where information exchange is mandatory, the subsequent collaborative negotiating of meaning may lead to efficient language learning through the participants noticing new words or language forms. This attractive idea lead to a large number of 'negotiation for meaning studies' being undertaken within the growing tradition of task-based language teaching (TBLT). However, these studies have had a "rather narrow focus" (Samuda \& Bygate 2008, p.117).

\section{The choice of topic-based questions as initial stimuli in the Institute online context}

One of the reasons why the need for a convergent task outcome has been emphasized in TBLT seems to be a belief that language students in institution- 
alised settings will not be motivated to continue with tasks unless there is the incentive of reaching a final goal. In other words, if participants are given more open-ended tasks, they will not necessarily continue the dialogue.

This kind of extrinsic goal-orientated motivation was not deemed necessary at the Institute where the participation of volunteer native speakers who strongly empathise with the students due to the discrimination they are suffering, together with the excitement for the students of their first meeting with native speakers, represents an unusually strong intrinsic motivation on both sides. Indeed, student questionnaire responses prior to the present study asked for more and longer conversations, while CFs have reported conversations which sometimes last for two or three hours. Feedback, including quantitative questionnaire data indicates that participants enjoy the conversations for their own sake, especially the informal chit-chat.

Another reason why more open tasks were preferred in the Institute context was because of logistical and technical hindrances. It is difficult for CFs to organize students in pairs or small groups since one or more students may have problems with their internet connection. This means that CFs need to be very flexible. In this situation it is not advisable for CFs to spend a lot of time in advance trying, for example, to organize a jigsaw task where different students hold different kinds of information which should be shared. As Hampel (2006, s.111) notes:

we have to ensure that tasks are appropriate to the medium used and that we develop tasks that take into account the affordances (ie the constraints and possibilities for making meaning) of the modes available.

Task design was also limited by students' poor internet connections which meant that audiographic conferencing was not possible. To avoid the danger of technical breakdown or overload, it was felt that the conversation assignments should be simplified to avoid students having to attempt to switch computer screens as the conversations progressed. This decision meant that any materials which students were to use would have to be sent and studied before the conversations so that students would not be expected to have materials on the screen in front of them while attempting to converse. They would simply have the Skype screen in front of them with the possibility of written chat.

Despite these practical limitations, the Institute still wanted to give the students some simple materials to prepare in advance since "pre-task planning has been widely shown to result in greater fluency" (Samuda \& Bygate 2008, p.113). As a result of all these considerations, a set of relatively simple, topicrelated questions were created as the initial stimuli for the conversations. The rationale was that the students would mentally prepare answers to these questions which would form a kind of safety net, guaranteeing an initial information exchange and serving as a starting point, branching off to the 
development of informal conversation about participants' families, their daily lives, interests and concerns. By these means it was hoped that CFs and students would develop strong personal relationships, which would reinforce learning and fluency in a positive dynamic spiral. The task was thus conceived of as a resource or support, rather than as the pedagogical driving force.

O'Dowd and Waire $(2009, \mathrm{p} .176)$ have noted that the potential pitfall of such informal discussion tasks can be that the exchange may proceed "without processing" or "without challenging input". The Institute conversation task designers hoped that these dangers would be countered by the progression and stimulus of the personalised informal interaction outlined above, gradually leading to the natural introduction and exploration of fresh input and ideas of mutual interest drawing on the participants' human experience and the exploitation of the native speakers' expertise.

Therefore, the first research question in the present study sought to investigate the adequacy of this task design, constrained as it was by technical hindrances and limitations in the online context.

\section{The CFs' role in enabling optimal patterns of interaction}

An emphasis on the importance of the individual's orientation, motives and goals in determining their level of participation in learning activities is part of the sociocultural approach underlying the present study. The individual learner's engagement is expressed in their role as an actor who is always "co-constructing the activity they engage in, in accordance with their own socio-history and locally-determined goals" (Ellis 2000, in Hampel 2006, p.109).

Conversations, which connect thoughts and utterances in a meaningful context, can simultaneously open up for the 'unexpected',' and contain the seeds of what Van Lier describes as "contingency", which he claims "lies at the core of the Vygotskian sociocognitive interface" (Van Lier, 1996, p.169). In simple terms, contingency promotes the unexpected and prevents stagnation.

One of the most important conditions and consequences of enabling such "contingent" interaction to occur is the encouragement of student activity and initiative. The extent to which the Institute's students' initiative and activity could be encouraged was therefore assumed to be a key influence on the patterns of interaction in the conversations.

As indicated above, CFs and students are encouraged to become friends. CFs do not need to hold a professional distance to their students. This implies that there is a greater potential for open symmetrical dialogue, which is "genuinely co-constructed" in the Institute setting (Gibbons, 2006, p.114), as compared to what is possible in a normal institutionalized setting. This may make it easier for conversations to go beyond the most common classroom mode of interaction: 'IRF' ( Initiation (I), Response (R), Feedback (F)) mode. 
Even though instructional forms of IRF can undoubtedly be useful and necessary, especially for lower level language learners, excessive use of IRF may give students little influence over topic development.

The aim of the second research question in this study was therefore to investigate which patterns of interaction were evidenced in the conversations and to what extent they appeared to be conducive to language learning. The analysis of the interviews investigated to what extent CFs reverted to traditional IRF patterns and to what extent the roles the CFs chose allowed for more equal power relations freeing up a greater degree of student initiative.

\section{Method}

\section{Participants: CFs' backgrounds}

The Conversation Facilitators (CFs) live in several different countries. They are either native speakers of English or have been living in English-speaking countries for many years and are equally divided between men and women with an average age in the late 40s. The interviews were done with CFs from two different courses: EFL101 and EFL102, four from each course. The EFL101 course is aimed at lower-intermediate students, EFL102 is for intermediate level.

\section{Design and validity}

In the first part of the present study the role of the researcher is as 'researcherpractitioner' or 'action-researcher' deeply involved within the organization, seeking to find ways to improve the conversations.

The study uses a qualitative method: semi-structured interviews with eight CFs designed to provide a greater depth of knowledge and insight than is otherwise available to the researcher. A form of triangulation is needed to enhance the validity of the study. This means including evidence from two other viewpoints in addition to the perspectives of the interviews. This different evidence can serve to partially substantiate, or negate the interview findings (Cresswell \& Miller 2000; Robson 2002; Richards 2003). One such viewpoint is available to the researcher through his role as Institute administrator for the conversations, with daily access to large amounts of written and oral communication with CFs and students in the form of e-mails, course-site messages and the researcher's frequent informal discussions with CFs and students. Another perspective is provided by the analysis of written evaluation questionnaires from both students and CFs. These however will form the subject matter of the second article in this study together with micro-analysis of transcripts from conversation recordings.

In addition to the different forms of evidence described above, a kind of pragmatic validation lies inherent in the close contact between the actionresearcher and the other Institute EFL administrators and teachers, as well as the 
CFs and students, all of whom are regularly consulted and have vested interests in the research producing valid results. This regular ongoing "cross-checking" of progress and suggestions largely eliminates the danger that the action-researcher will become so subjectively involved with one narrow focus that he loses the "outsider's" detached perspective.

\section{Procedure}

The interviews were semi-structured, with six initial questions (see Appendix D) as the starting point opening up into more flexible exchanges. Each interview was conducted over Skype in the period $30^{\text {th }}$ June to $20^{\text {th }}$ July 2007. The interviews lasted between $30-90$ minutes. The conversations were recorded in note form during each individual conversation and then written up in full, including the quotations presented in the findings.

The interviews were coded, categorized and analysed according to two main meaningful dimensions. First, similarities and differences in respondents' answers were identified. Second, the material was grouped according to central ideas and themes identified in the relevant theory as outlined above. This lead to the development of concepts for discussion, which are "increasingly abstracted from, but consistent with individual accounts" (Blee \& Taylor, p.111 in Klandermas \& Staggenborg (Ed.) 2002).

\section{Findings}

The findings from the interviews are divided into three sections: first some general findings applying to all CFs, second the findings specifically relating to the EFL102 CFs, and third the findings for the EFL101 CFs. The latter section includes data from two interviews which are presented in-depth because they represented examples of "best practice".

\section{General findings for all CFs}

There was agreement among all the CFs who were interviewed that it was useful to have some basic questions (language and content 'input') to help start the conversations because, in the words of different CFs, these can provide a "map", "framework" or "mental schemata" for the conversations. The CFs also agreed that it was important that the students are prepared by thinking about the assignment questions, since this made them look up difficult words and think about the topics in advance of the conversations.

However, there were notable differences in the ways in which the different CFs used the conversation assignment questions during the conversations. These variations were to some extent due to differences in the content of the course materials between the two courses: EFL101 (aimed at lower-intermediate level students) and EFL102 (intermediate level students): The theme of the lower course (EFL101) is more practical, focusing on sub-topics which are simpler and 
more familiar compared with the more academic sub-topics on EFL102 (see appendix B for details of themes and sub-topics).

\section{Findings for EFL102 CFs}

The responses from those volunteers serving on the higher course (EFL102) indicated that the relatively more advanced subject matter for the EFL102 conversation assignments created a challenge to make discussions on the course material linguistically accessible. The way the EFL102 CFs responded to this challenge is illustrated in the continuum in Figure 1:

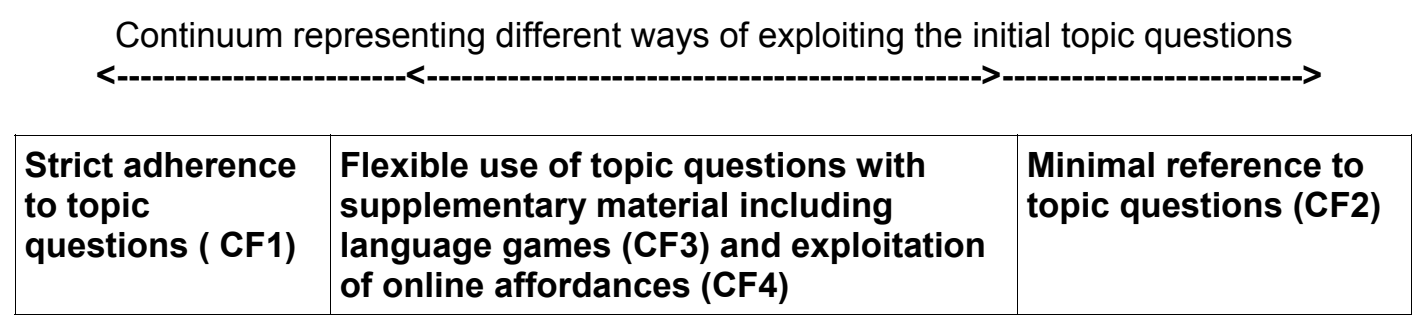

Figure 1 Illustration showing how EFL102 CFs used the topic questions

The left side of the continuum represents one of the CFs (CF1) who reported sticking firmly to the initial task questions in the belief that students needed to get used to talking about academic-style assignments, even though it became apparent that the topics did not always attract students' interest. This decision seems to have led the CF to resort to more rigid types of "IRF" as the mode of interaction remained formal. The other end (right side) of the continuum represents another EFL102 CF (CF2) who started off by trying to conduct the conversations without any formal structure ("I'll talk about anything...peanut butter....."), effectively ignoring the topic questions if she could get her students to talk about other things. This CF reported that the dialogue stayed far away from the original topic questions with the result that her students may have been wondering why they should have bothered preparing the topic questions at all.

In the middle of the continuum, the two other EFL102 CFs (CF3 and CF4) were able to use the assignment questions more flexibly. One of them (CF3) found that the EFL102 topics "struck a chord with the students due to the spiritual content of the questions". (The significance of this remark in the specific context of this study is more fully explained in the discussion section). CF3 also used language games with his students. It appears that this CF may have had some students who were above the normal intermediate level.

The fourth CF (CF4), who was highly computer literate, made active and extensive use of online affordances (available sources of additional stimuli) to enrich the learning environment and provide new challenging input in the form of materials and internet links of interest which he sent to his students between and during conversations through the Institute course site messaging system and 
through the Skype written chat-box and file-sending facility. It seems clear that CF4's students greatly appreciated these services. By bringing in these extra resources, this $\mathrm{CF}$ created flexibility and alternatives to rigidly following the assignment questions. He was able to switch from the topic questions if the conversation started to stagnate or comprehension became difficult, using other materials or more everyday chit-chat, before returning to the initial topic at a later stage.

\section{Findings for EFL101 CFs}

Due to technical difficulties (line breaks), two of the EFL101 CFs (CF5 and CF6) faced the challenge of holding one-to-one conversations with weak students. Despite great patience and excellent listening skills, CF5 struggled to promote a dialogue, being forced to rely on closed-ended questions and short responses because his students were shy and lacked sufficient vocabulary and comprehension skills. CF6, who was bilingual, was also unable to progress beyond short answer responses. She resorted to translation and Persian.

These two EFL101CFs who tried to talk with only one student at a time, were only able to engage in limited exchanges in English, having to rely on repeated prompting and simple closed questions. It was not possible for CF5 and CF6 to open up and develop the dialogue. In contrast, the other two EFL101 CFs (CF7 and CF8) were able to operate over a much broader dialogical range as represented in the IRF/open scale in Figure 2:

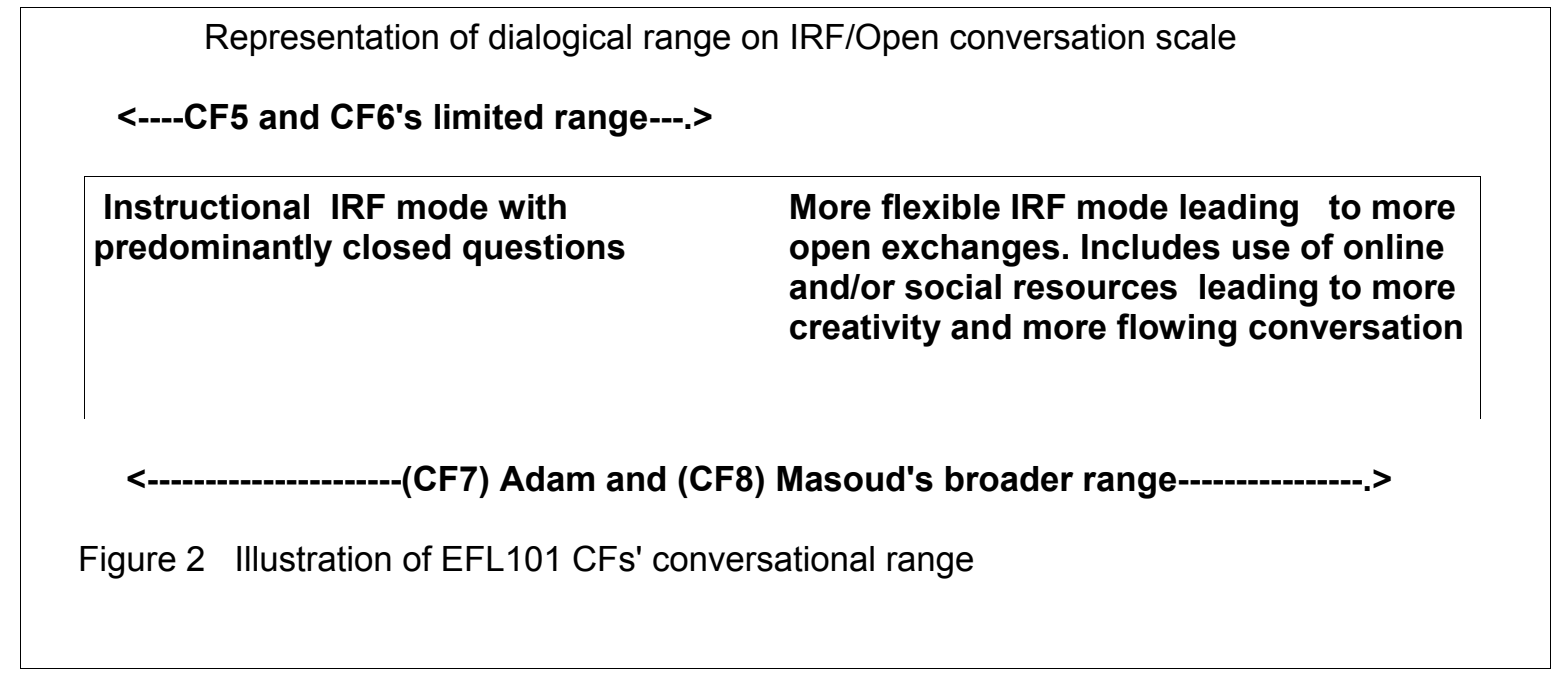

\section{Examples of best practice: in-depth analysis of two EFL101 CFs: Adam and Masoud}

The findings from the interviews with CF7 (hereafter referred to as Adam) and CF8 (referred to as Masoud), are in the following presented in further detail as examples of best practice: 


\section{Adam}

Adam is a 28-year-old Australian who came to live in Norway 3 years ago. $\mathrm{He}$ has well-developed communication skills, is trained in Public speaking and has worked in customer relations. He has excellent PC skills and his own professional website and has been using Skype for several years. Adam preferred to hold the conversations with at least two EFL101 students on the line at a time, consciously helping to bring together students who didn't know each other.

For Adam, a young person with well-developed PC skills and Skype experience, it was natural to integrate the use of the Skype chat-box into the conversation experience. He says that he "finds the chat a very good support tool". While some CFs restrict the written 'chat' to a minimum because it is not "conversation" in the strict oral sense, Adam senses no conflict between the written 'chat' aspect and the oral conversation. Instead he attempts to exploit the 'hybrid' nature of the discourse by using the chat-box not only to overcome breaks in the conversation caused by the students' weak internet connections, but also to consciously overcome cultural differences, find common ground and thereby develop 'intersubjectivity' (mutual engagement) between himself and the students and between the students themselves.

Adam describes how he used the written chat facility in three different ways: first, to make use of linguistic resources, second to bring into play social resources, third to encourage creativity.

He uses the chat mainly to support correction or resolve misunderstanding or negotiate meaning. If there is doubt about a word or even a whole question, he might write the word or question in the 'chat' at the same time as he says it. For example, when a student misunderstood the difference between "rarely" and "really", he wrote the word "rarely" in the chat and explained its meaning. He will often write words in the 'chat' if they seem unfamiliar for the students. In fact he uses the chat much as a teacher might use a blackboard, or more appropriately, a whiteboard.

Second, Adam uses the chat to help create friendships and "break the ice": He provides links to his personal photos because he says the students "want to know about our lives" (ie. the CFs' lives), therefore he says "it is important to personalize the relationship". Once Adam knows which field of study his students have, as well as their main interests and hobbies, he will try to find and send the student relevant internet links, including information or links about what is happening in Australia or Norway (Adam's adopted homeland) relating to the students' fields of interest.

Third, Adam has used the 'chat' to bring variety and creativity to the conversations. He describes how he played a game with the students to illustrate the difference between "chat English" and the kind of formal English, which the students need to produce in their academic written assignments. As examples he 
used the abbreviated forms " $u$ " (you), "2" (to), "coz" (because) and "wanna" (want to). In this way he raised the students' awareness of this important issue.

Partly through his facility with the use of the chat, and also through his naturally open personality, Adam seems to maintain his students' attention and encourage them to 'open up'. In this way, he draws closer to them and can engage with them in other more creative activities. He says he prefers "creative" conversation assignments, explaining that students best learn language when they have to "think on their feet". He gives as an example the only EFL101 assignment which asked students to use specific vocabulary words in relation to a topic. He got his students to use the new words, deliberately "getting them to make mistakes so they learn" (!) ....... "because often your greatest learning is when you make a mistake". Adam's sense of fun and the importance he attaches to humour in learning, combined with sensitivity allows him to do things others might avoid. "Exercises in 'tripping people up a bit' can help them to learn".... he adds.

When discussing possible types of conversation assignment, Adam asserts that "true learning would happen if they (the CFs) had to ask questions on the spot" (rather than use the pre-prepared questions in the present conversation assignments). However, he also acknowledges that students don't always feel "comfortable" entering "unknown territory", that they "want to feel quite safe" and that they "want to get it right". Therefore, despite his conviction of the "ideal" of students having to "think on their feet", Adam admits that he usually toes a pragmatic line, "sticking to the questions", because he "doesn't want to stress the students out ${ }^{n}$.

\section{Masoud}

Masoud was just over 50 years old when this interview was conducted. Born of Iranian parents, he came to England as a youth. He worked as a school teacher for many years, though not generally as an English teacher, so he had a great deal of experience in managing classrooms. Masoud worked for several years with students with special learning difficulties and developed an extraordinary ability to listen beyond words. He was very comfortable teaching conversation over Skype.

Like Adam, Masoud always tried to talk with two or more students at a time, emphasizing the importance of encouraging a group dynamic. His personal interests included singing and playing guitar, both of which he introduced during the conversations. Masoud had a very deep understanding of how to develop the conversations in order to engage the students and ensure meaningful interaction. Though he knew Persian, Masoud deliberately did not use it in the conversations.

Masoud repeatedly emphasized the "paramount importance of building good relationships with the students". He felt that the conversations were worthwhile "as long as the students feel empowered and elated". This conscious emphasis 
on "empowering" students, combined with Masoud's pedagogical knowledge, skills and experience seemed to allow him to find means by which to cross the 'switch-over' point, which Van Lier identifies as the critical move from IRF mode to more open learner discourse (in Candlin and Mercer (Ed.), 2001).

With reference to the general findings and the role of the conversation assignment questions in shaping the interactive pattern of the conversation, Masoud insisted that the initial questions need to be used "flexibly", not "rigidly". When he first started doing the conversations, he says that students would come to the conversations with prepared written answers which they would read from. Since Masoud felt that this was not appropriate to "conversation mode", he stopped giving the assignment questions to the students in their original written form. Instead, he introduced the conversation with a "kind of preamble" or general "chit-chat" focusing around the topic to be discussed, gradually "easing" the students into the conversation. He then rephrased the original questions, forming new questions which "go off at tangents and angles" to the original assignment questions. Masoud says that the result is that the students do not prepare their answers as much as before, but that they do still think about them because they know that they will be expected to contribute to the discourse without necessarily answering the original questions.

As an experienced teacher, he recognizes the importance of the CF thinking about the topic in advance in order to be able to "keep the conversation going". He suggests two possible approaches to a topic, either going from the whole to the parts or from the parts to the whole. He says that he prefers the former approach "in conjunction with a personal experiential level, going to deeper layers $^{n}$. For example, in the conversation about transport in EFL101 (see appendix E), he started by asking the students about the different types of transport they used, followed by more probing analytical questions.

Masoud spent a lot of time assisting weaker students. He explained that it is important that students are not asked in an "intimidating" fashion, but rather in conversation mode. He emphasized that the CF needs to "walk" with the students at the level they are at. Thus, weaker students need to be given more 'closed' questions, "including yes and no" questions, to build their confidence, while "the range of questions can gradually be expanded".

\section{Discussion}

Moving on from the individual styles represented by Masoud and Adam, the findings as related to the research questions can be summarized as follows: The design of the conversation assignments sets the agenda for the conversations. The question and answer format and the level of abstraction of the different topics affect the progression of the conversations and the patterns of interaction which are also influenced by the number of student participants (one-to-one or 
small group). Finally, particularly successful CFs use ingenuity, pedagogical experience, technical skills and perseverance to try to overcome technical and linguistic obstacles.

The following discussion addresses the challenges of providing the weaker EFL101 students with appropriately-designed conversation assignments, the need to change some of the topics and tasks for the EFL102 conversations, and the implications of the study for audio conferencing in other online contexts.

\section{The challenge of task design for weaker students using audio conferencing}

Rosell-Aguilar (2005, p.8) points out that beginning foreign language learners "require a larger number of stimuli and more structured activities to extract the little language they can producen. This was a particular challenge for the two EFL101 CFs who attempted to converse one-to-one with weaker students. These students were not able to put together simple sentences without substantial support. Rosell-Aguilar (ibid.) further suggests that socio-cultural factors "may not affect the co-construction of the activity as much as has been argued".

The Institute had hoped that the unique sociocultural factors in the Institute conversation situation, consisting of the presence of highly-motivated volunteer native speakers and eager students, might be sufficient to override the obstacles for CFs attempting to communicate with students with low oral proficiency. However, the interviews left no doubt that the two EFL101 CFs who tried to talk with weaker students one-to-one were unable to move beyond simple closeended questions which their students could only give very short answers to, and sometimes could not understand at all. Furthermore, these two CFs were not proficient with Skype and did not make significant use of the course site messaging system between conversations, so they were unable to make use of the online affordances. Their conversations sessions with weak students and frequently broken internet connections seem to have been very demanding for all the participants.

On the other hand, the small groups of EFL101 students with whom Masoud and Adam facilitated relatively successful conversations with, were also weaker lower-intermediate students. It appears that Adam and Masoud succeeded because, as interaction progressed, their approaches generated contingency as they were able to provide new challenging input at appropriate levels relative to their students' ZPDs. One of the keys which seems to have unlocked these students communicative abilities, encouraging them to take risks and make mistakes appears to have been the social stimuli and support which the other students in their pairs or small groups provided, in combination with Masoud's pedagogical experience and Adam's skilful use of the online affordances. In other words, these CFs seem to have collaborated with their students to genuinely co-construct their conversations. 


\section{Bypassing technical obstacles: two alternatives to the present task design for weaker students}

One of the most difficult challenges which has arisen as a result of the findings in the Institute context, is how to develop and improve conversational tasks with weaker students who sometimes have difficulty understanding questions and can usually only give short answers.

One possibility is to break with the policy of not expecting students to bring printed material with them to the conversations. Those students with better connections can switch screen, from the Skype screen to a file where they have copied simple preparatory material from the course site, while students with poorer connections would need to print out the task materials and bring them to the conversations. Tasks could then be designed by for example using simple drawings, pictures or picture stories together with common words and expressions, and students could converse with these in front of them. These would provide an extra stimuli which CFs could exploit in the form of questioning and prompts possibly linked to simple tasks like "fill in the blank", or asking students to create sentences or short narratives, with the CFs providing extra lexical items or correction through a combination of written chat and conversation. This could provide an alternative by slowly building weaker students' oral fluency.

A second possibility is to provide weaker students with simplified story books with listening $C D$ which are cheap and available in Iran. Practising listening and reading could provide the preparation for the conversations for weaker students which might then consist of CFs asking questions about what the students had listened to, with a progression of increasingly difficult questions starting with closed questions testing comprehension and then moving to more open-ended discussion of content. The questions could also be sent to students in advance of the conversations and they could make preparatory notes, print out the questions or copy them to a simple file which they could view while the conversation progressed.

\section{The need to change the topics and tasks for some of the EFL102 assignments}

The overall impression left by the interviews with the CFs on EFL102, was that the subject matter of the conversation assignments was sometimes too abstract and too far removed from students' 'day to day' reality. In practice, this meant that the level of language required for discussion of some subjects was beyond the ZPD level at which students could be assisted towards self-regulation. Therefore, for some students and CFs, these tasks will have progressed "without processing" (O'Dowd \& Waire 2009, p.176), either because the input was too challenging or because the material was not sufficiently interesting for the students to motivate continued discussion on the topic. 
The varied responses of the EFL102 CFs showed that the skill and flexibility of the CFs in staying 'on topic' or moving to other subjects was a crucial factor in maintaining students' motivation. On some topics, the spiritually orientated subject matter seemed to act as a significant motivational factor for some CFs and students, sourcing their common faith and causing them to make extra efforts to communicate their opinions on subjects which touched them deeply, despite the apparent inaccessibility of some of the language for these topics. This means that even though certain conversations do appear to successfully tap into the Institute participants' socioculturally-determined goals and orientation, there still seems to be a need to introduce more learner-centered topics and a greater variety of tasks on EFL102. The choice of new topics should reflect students' interests and everyday lives rather than being tied to the EFL102 course sub-topics. There are normally two conversations on each module, so one of these could still be tied to the module sub-topic while the other conversation task on the module would no longer need to be connected to the course material.

Different tasks to combine with or replace some of the present topic-based discussions could include simple role plays or narrative retelling, student presentations, debates or language games using lexical items including idioms which often promote humour as they cross cultures.

\section{CFs' technical skills and the exploitation of online affordances}

The interviews showed that the CFs' approaches to the conversations are based on their personal skills and personalities. However, whatever the CFs' personal backgrounds may be, their chances of having successful conversations will be improved if they develop their computer skills and take advantage of online affordances.

For example, the EFL101 CF Adam and another technically proficient EFL102 CF (CF4) were able to use the online environment to connect physical and cognitive links and threads, thereby facilitating "contingent" talk, where "utterances are constructed on the spot" (Van Lier, p.99, in Candlin \& Mercer, 2001). As Adam pointed out: "a true conversation is sort of spontaneous".

Adam and the particularly computer literate CF understood that what happens before and after conversations, can be as important as what happens in the conversations themselves. In other words, by communicating regularly with students between conversations and providing them with messages of support as well as stimuli in the form of materials and internet links which matched their interests, these CFs were able to provide extra stimuli which allowed and promoted the unexpected and spontaneous in their conversations.

\section{CFs' pedagogical skills and the promotion of student activity and initiative}

Next, the interview with Masoud showed how it is possible for CFs to progress beyond a rigid IRF mode, even with weak students. By encouraging students to 
listen to each other he consciously "avoided directing the conversation all the time", rather seeking "a circular conversation", and trying to "get the students to accept him as a participant on a level with them". Masoud sought the role of moderator in a truly symmetrical dialogue. In this way he said that he did not have to "interfere" as the conversation progressed. This sometimes led to the students "babbling away" (in English). At this stage, Masoud explained that he sometimes "couldn't stop them".

Masoud's descriptions are signs of the 'flow' which Csikszentmihalyi (2008) writes about in his book about optimal psychological experiences. This is perhaps the hallmark and ultimate sign of success for any $\mathrm{CF}$, if one accepts the crucial role of student orientation, engagement and participation as preconditions for learning. In this way, Masoud showed what was possible. As he remarked, it is not "his" conversation, "it's the students'......or rather it's a partnership". These words illustrate the fundamental humility which underlies Masoud's approach, but beyond that humility is an attention to detail in planning which other CFs would do well to emulate.

Even though the CF's role is as a facilitator and not a formal teacher, as in teaching, good facilitation requires thorough preparation. This means that the CFs need to consider the topic or assignment in advance, thinking about possible directions the conversation could take, and jotting down notes or possible questions. With experience, such planning and mental reconnaissance can stimulate the development of more spontaneous interaction once conversations are underway.

Of further interest in understanding the practical steps Masoud took to promote symmetry and "true dialogue", was his attitude towards silences. Whereas one of the other CFs stated that "the silences had her "tearing her hair out" ", Masoud stated that he was "not afraid of silences though some may be embarrassed". He reasoned that silences are normal in most conversations allowing people time to think. So if there is a "long extended silence" it would not necessarily be Masoud who broke it. He maintained that there is no need to "push" the conversation, "it will take its own turns". This is interesting because it seems to be in stark contrast to the proposition that language 'negotiation' should be as frequent as possible in order to maximize learning opportunities. In reality, creating learning opportunities cannot be induced in such a mechanical way.

The interviews indicate that when CFs "walk" with their students at whatever level they are at, framing alternatively open or closed questions as appropriate while maintaining support and scaffolding, only gradually widening the frame as students develop confidence, signs of self-regulation and fluency will start to appear.

\section{The socio-affective foundation for the conversations}

To sum up, in the majority of cases, these online conversations are the EFL101 student's first meetings with a native speaker. The fragility and vulnerability of 
these first meetings with CFs with different national and cultural backgrounds can be compounded by technical difficulties and background expectations framed through students' experiences in an authoritarian education system. This makes some students very shy and nervous. Above all, they need to be constantly encouraged.

Under these circumstances, patience, perseverance, humility, empathy, flexibility, a good sense of humour and a range of other personal qualities are required from the CFs in order to nurture students to overcome initial shyness and feel relaxed enough to participate fully. Trust and confidence is the key, which seems to unlock the students' willingness to take chances, to activate previously passive lexical capacity and to thereby potentially expand the zones of proximal development to be mediated.

According to the interviews, the CFs who appeared to be most successful all seemed to place considerable emphasis on, where possible, bringing students together socially and assisting them in getting to know one another. The Institute students are generally very grateful for the opportunities to get to know other students in this way since one of the major problems they are facing is social isolation. The importance of the persistence of the CFs in facilitating such social interaction by overcoming technical obstacles can hardly be overestimated.

\section{Conclusion}

\section{Implications for foreign language teaching and further research}

In answer to the first research question, it is clear that while the most proficient CFs manage well with the present topic-based questions, there is a need to introduce new tasks for weaker students though this implies that students will need to bring printed resource materials with them to the online conversations. For the intermediate students who already possess sufficient linguistic resources to interact more easily, increased task variety and more student-centered topics can offer relief for struggling CFs and students.

In answer to the second research question, the interview findings have provided good indications of the kind of technical and pedagogical skills which can promote language learning in the Institute environment. Changes and improvements in the task designs indicated above should make it easier for less pedagogically experienced CFs to interact with students at the appropriate level for learning.

In Norway, as in the rest of the world, there is increasing use of both audio and audiographic conferencing to promote oral proficiency for foreign language learners. This trend is likely to continue, a development which Norwegian language teachers will need to exploit to the full. The present study underlines the importance of carefully designing tasks appropriate to the specific sociocultural context and in relation to the technical affordances. 
This means that in an audio conferencing environment, if learners (and teachers) can be encouraged to interact socially and collaborate, the resultant linguistic stimuli drawn from the participants' inner resources may be used to partially compensate for a lack of outer sensory stimuli.

Though the Institute context is unique, the importance of identifying and harnessing learners' motivations according to the sociocultural circumstances is common to all online learning contexts. Similarly, the consciously planned development of learners' and teachers' technical proficiency and support thereof is a key factor.

Even though this study has concentrated on the promotion of fluency without any specific focus on language form, accuracy or complexity, there is little doubt that most CFs, in their capacity of being well-educated native speakers, do have the capacity to teach specific lexical items and simple grammar. Bilingual CFs also potentially posess special knowledge concerning the differences between English and Persian which they may usefully be able to impart to students. Therefore, important questions for further research on the Institute EFL programme concern the way and extent to which CFs can or should function as language teachers and to what extent such a role might conflict with or complement that of $\mathrm{CF}$. These issues will form the research questions for the second part of this study and have relevance to other language teaching institutions where native speakers participate in audio exchanges. Examples would be in tandem or tridem telecollaborative exchanges which are growing in popularity worldwide.

\section{References}

Aljaafreh, A. \& Lantolf, J.P. (1994). Negative Feedback as Regulation and Second Language The Modern Language Journal Vol.78 (4), 465-483.

Arcos, B, De Los. \& Coleman, J.A. \& Hampel, R. (2009). Learners anxiety in audiographic conferences: a discursive psychology approach to emotion talk. ReCALL 21 (1), 3 -17.

Barrett, K. A. (2008). An exploration of EFL teachers' and learners' lived experiences in a synchronous online VOIP- enabled cross cultural language learning environment.. Ph.d Dissertation, The University of New Mexico

Belz, J.R. \& Thorne, S.L.(2005) (Eds.), Internet-Mediated Intercultural Foreign Language Education. Aausc (American Assosiation of University Supervisors and Coordinators). Florence KY: Heinle

Blee, K.M. \& Taylor, V. (2002). Semi-structured interviewing in social movement research. In Klandermas, B. \& Staggenborg, S. ( Ed.) (2002), Methods of Social Movement Research. University of Minnesota Press.

Chang, L-Y. (2007). The use of structured instant online discussion to enhance college students' English oral proficiency. Master's thesis: Taiwan: Graduate Institute of Education. Retrieved from : http://www.ethesys.lib.ncku.edu.tw/

Common European Framework of Reference (CEFR) for Languages. (2001). Council of Europe.

Candlin, C. N., \& Mercer, N. (Ed.). (2001). English language teaching in its social context. New York: Routledge. 
Cresswell, J.W., \& Miller, D. L. (2000). Determining Validity in Qualitative Enquiry. Theory into Practice, 39(3), 124 -130. The Ohio State University.

Csikszentmihalyi, C. (2008). Flow: the psychology of optimal experience. Harper Collins: New York.

Doughty, C. \& Long, M. H. (2003). Optimal Psycholinguistic Environments for Distance Language EFL learning. Language Learning and Technology, Vol.7((3) 50 -80.

Felix, U. (2004). Performing beyond the comfort zone: Giving a voice to online communication. In: Atkinson, R., McBeath, C., Jonas-Dwyer, D. and Philips, R. (eds.) Beyond the comfort zone: Proceedings of the 21st ASCILITE Conference, Perth, 5-8 December.

Gibbons, P. (2006). Bridging Discourses in the ESL Classroom. London - New York, Continuum.

Hampel, R. \& Hauck, M. (2004). Towards an effective use of audio conferencing in distant language courses. Language Learning and Technology, Vol.8 (1), 66- 68.

Hampel, R. (2006) Rethinking task design for the digital age: A framework for language teaching and learning in a synchronous online environment. ReCALL 18(1), 105-121.

Hauck, Mirjam (2007). Critical success factors in a TRIDEM exchange. ReCALL, 19(2), 202223.

Hong, B.T.M. (2006). Teaching Speaking Skills at a Vietnamese University and Recommendations for Using CMC. Asian EFL journal, Volume 14, Teachers' Articles, August, Article 2.

Kennin, M-M. (2010). Differences that make the difference: a study of functionalities in synchronous CMC. ReCALL, 22(1), 3-19.

Kötter, M. (2001). Developing Distance Language Learners' Interactive Competence - Can Synchronous Audio Do the Trick? International Journal of Educational Telecommunications, Volume 7(4), 327-353.

Lafford, A. \& Lafford, B. A. (2005). CMC Technologies for Teaching Foreign Languages: What's on the Horizon? CALICO Journal Vol 22(3), 679-709.

Lamy, M-N. (2004). Oral Conversations online. Redefining oral competence in synchronous environments. ReCALL, 16(2) pp.520-538.

Lamy, M-N. \& Hampel, R. (2007). Online communication in language learning and teaching $n E W$ yORK: Palgrave Macmillan

Lee, L.(2008) Focus-On-Form through Collaborative scaffolding in Expert-to-Novice Online Interaction. Language Learning and Technology, Vol 12(3), 53-72.

Maclean, G.R. ( 2009). SMILE! Students Meeting for Intercultural Learning and Exchange retrieved from http://ejournals.thaicyberu.go.th/index.php/ictl/article/view/9

Mahfous, M.S. \& Ihmeideh, F. M. (2009) Attitudes of Jordanian university students towards using online chat discourse with native speakers of English for improving their language proficiency. Computer Assisted Language Learning, 22(3), 207-227.

Nunan, D. (2005). Language Learning \& Technology, Vol. 9(3), 2-3.

O'Dowd, R. \& Ritter, M. (2006). Understanding and Working with Failed Communication in Telecollaborative Exchanges. CALICO Journal Vol 23 (3).

O'Dowd, R. (2007) ( Ed.). Online Intercultural Exchange: An Introduction for Foreign Language Teachers. New York: Multilingual matters

O'Dowd, R. \& Waire (2008). Peer feedback on language form in telecollaboration. Language Learning and Technology, Vol 12(1), 43-63.

O'Dowd, R. \& Waire, P. (2009). Critical issues in telecollaborative task design. CALL, 22(2), $173-188$ 
Pica, T. Kanagy, R. \& Falodun, J. (1993). Choosing and using communication tasks for second language learning. In Crookes, G. \& Gass, S. ( Eds.) Tasks and language learning: integrating theory and practice. Clevedon, UK: Multilingual Matters: 35-56.

Pica, T. (1994). Research on negotiation: What does it reveal about second-language learning conditions, processes, and outcomes ? Language Learning 443, September, 493-527.

Robson, C. (2002). Real World Research. Oxford: Blackwell Publishing

Rosell-Aguilar, F. (2005). Task design for audiographic conferencing: promoting beginner oral interaction in distance language learning: CALL 18(5),. 417 - 442

Rosell-Aguilar, F. (2006). The face-to-face and the online learner: a comparative study of tutorial support for open and distance language learning and the learner experience with audiographic SCMC: The Reading Matrix, Vol 6(3), 248-268.

Richards, K. (2003). Qualitative inquiry in TEOSL. New York: Palgrave Macmillan

Samuda, V. and Bygate, M. (2008). Tasks in Second Language Learning. NewYork: Palgrave Macmillan.

Savignon, S. (2002) . Communicative language teaching: Linguistic theory and classroom practice. In S. Savignon ( Ed.): Interpreting communicative language teaching: Yale University Press.

Skehan, P. (1996) A framework for the implementation of task-based instruction. Applied Linguistics, Vol. 17 Number 138 -62. I

Thomas, M. (Ed.). (2008). Handbook of research on Web 2.0 and second language learning. IGI Global

Tsukamoto, M. \& Nuspliger, B. \& Senzaki, Y. (2009). Using Skype to connect a classroom to the world: Providing students an authentic language experience within the classroom CamTESOL Conference on English Language Teaching: Selected Papers Volume 5

Tudini, V. ( 2003) Using native speakers in chat. Language, Learning and Technology, Vol. 7(3), 141-159

Ur, P. (1996). A course in language teaching: Practice and theory. Cambridge: Cambridge University Press.

Van Lier, L. (1996). Interaction in the Language curriculum. Awareness, autonomy and authenticity. Harlow, England: Longman.

Volle, M.(2005) Analysing oral skills in voice e-mails and online interviews. Language Learning \& Technology Vol 9(3), 146-163

Yilmaz, Y. \& Granena, G. (2010. The effects of task type in Synchronous ComputerMediated Communication ReCALL 22(1), 20-38

Zhang, F. \& Barber, B. (2008). Handbook of Research on Computer-Enhanced Language Acquisition and Learning IGI Global. 


\section{APPENDICES}

Appendix A: Screenshots of Skype and Elluminate

Appendix B: Overview of BIHE EFL101 and EFL102 course themes and sub-topics

Appendix C: Excerpts from the CF Training document

Appendix D: Initial questions for the semi-structured interviews

Appendix E: Examples of conversation assignment questions 


\section{Appendix A}

Screenshot of Skype: used for simple audio conferencing with text chat

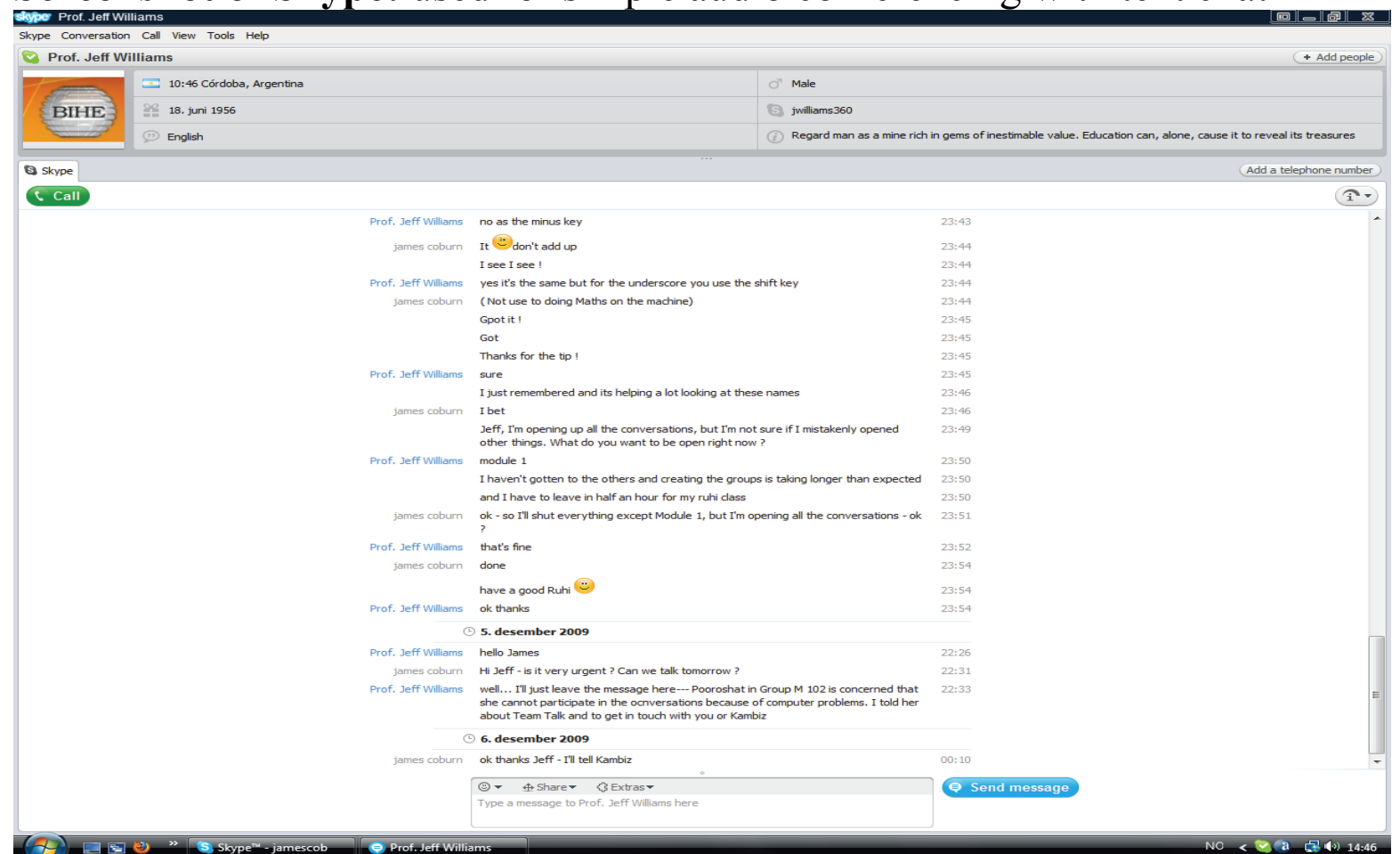

Screenshot of Elluminate: used for audiographic conferencing with whiteboard, symbol manipulation tools, audio conferencing and text chat. Sample from Open University German course.

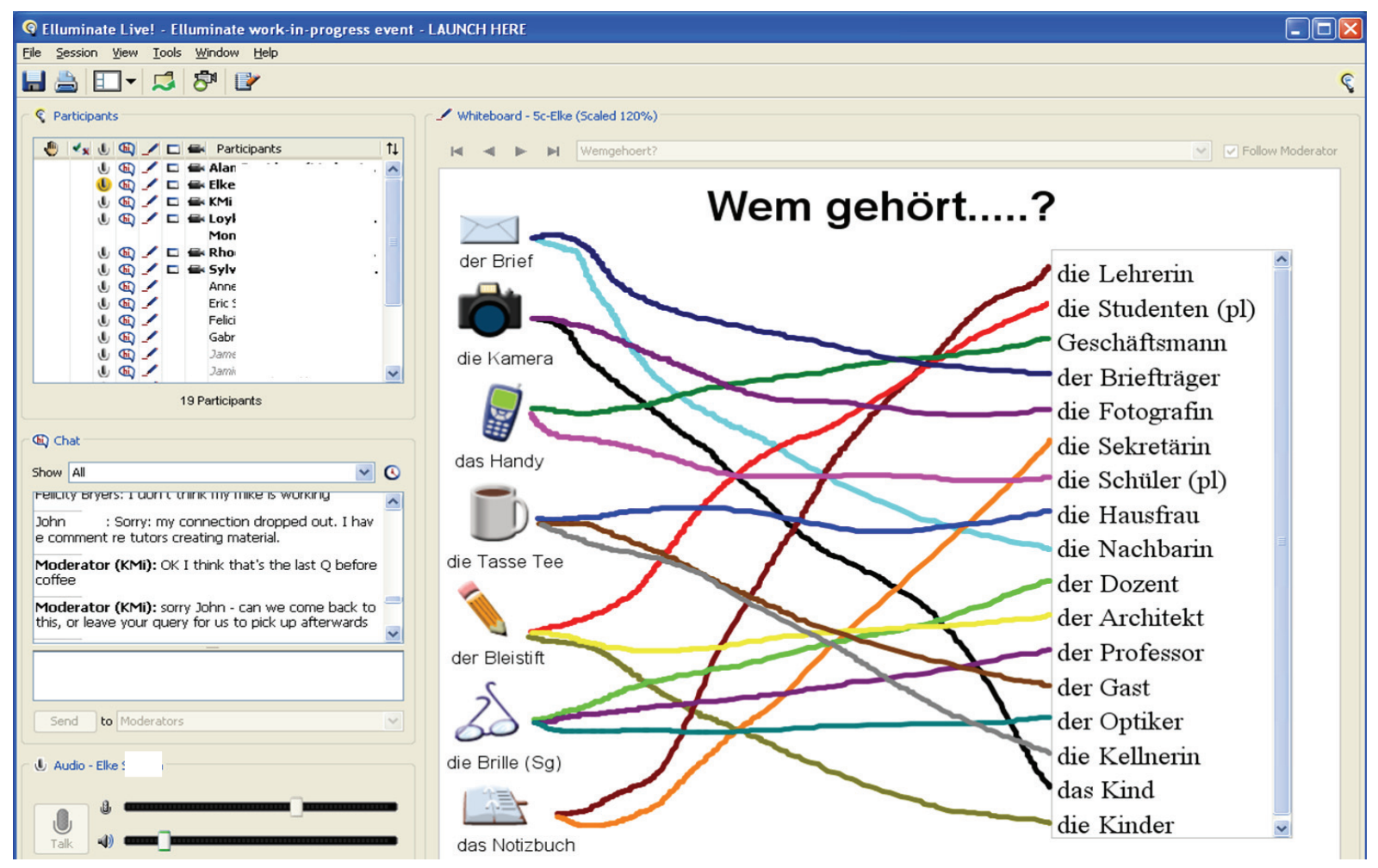




\section{Appendix B:}

\section{Overview of BIHE EFL 101 and EFL102 courses and sub-topics}

\begin{tabular}{|c|c|c|c|}
\hline course & theme & modules & content \\
\hline EFL101 & $\begin{array}{l}\text { New university } \\
\text { student }\end{array}$ & $\begin{array}{l}\text { 1. Getting to Know You } \\
\text { 2. Academic Achievement } \\
\text { 3. Health } \\
\text { 4. Traveling } \\
\text { 5. Global Challenges } \\
\text { 6. The Arts }\end{array}$ & Practical \\
\hline EFL102 & Peace Message & $\begin{array}{l}\text { 1. Is Peace Possible? } \\
\text { 2.The Human Spirit } \\
\text { 3.Moral Character } \\
\text { 4.Human Potential } \\
\text { 5.Material-Spiritual balance } \\
\text { 6.Unity in Diversity }\end{array}$ & Moral-ethical \\
\hline
\end{tabular}




\section{Appendix C:}

\section{Excerpts from the CF Training document:}

- The CF will probably find it helpful to make notes and keep brief records of the conversations and the students' level of participation.

- The CFs should try to avoid talking to the students "one to one" because the interaction between students is very important.

- Ideally there should be three or even four students together, but two students at a time is also acceptable.

- The CF should become friends with the students. There should be mutual respect.

\section{Encouraging active participation}

- Normally, the more the students talk the better it is.... It is natural that some students will talk more than others. If however, the CF notices that some students are silent or talk very little, she or he will need to try to encourage those students to say more. The CF should regularly acknowledge and encourage all the students' contributions. For weak students, the CF may need to prepare a range of very simple questions which the students can give short answers to. Gradually the range of questions can be widened as the weak student's confidence increases.

\section{Regarding correction:}

- It is best to avoid correcting too much. As long as it is possible to understand what is said, the conversation should be allowed to flow. When using Skype, some corrections can be discreetly indicated using the written "chat" facility.... The key here is sensitivity to the individual student: some welcome correction, for others, it may easily break down their self-confidence. 


\section{Appendix D:}

\section{Initial questions for the semi-structured interviews:}

1. How did you use the present conversation assignments?

2. How did the conversations develop?

3. What happened when students made mistakes, understanding broke down or new language was introduced?

4 What do you think about the present conversation assignments?

5 What extra input did you provide in addition to the conversation assignments?

6. How did you use the skype chat? 


\section{Appendix E}

\section{Examples of conversation assignment questions:}

\section{An EFL101 Conversation Assignment}

Travelling (from Module 4)

1. What means of transportation do you use when travelling in your country?

2. Which means of transportation is the safest in your country? Why?

3. Tell your tutor and classmates about one of your trips by train or plane.

4. What are the benefits of travelling by car?

5. What can be done to improve the safety of car travel between towns and cities?

6 . How can you help a foreign visitor see the various parts of your country?

\section{An EFL102 Conversation Assignment}

Virtues (from Module 3)

1 Which qualities or virtues do you think are the most important?

2. Which qualities or virtues are the easiest to have or the most difficult to develop?

3 Are there qualities that you feel you were born with and have naturally?

4 Is there a quality that you have developed in the past? How did you do that?

5 What is a quality you need to develop? How do you think you can do it? 